\title{
Increasing Trends of Leprosy - Still a Public Health Challenge
}

\author{
Valluri Anitha Lavanya, Rachamadugu Hymavathi", A. Surekha and C.N. Soumya
}

Department of Microbiology, Government of Medical College, Kurnool, Andhra pradesh, India

*Corresponding author

\begin{abstract}
A B S T R A C T
Screening of the patient's family for leprosy is an important step to reduce the incidence of leprosy and also helps family members to get early treatment after skin smear test

\section{Keywords}

Leprosy, Ziehl

Neelsen Stain

Article Info

Accepted:

10 March 2019

Available Online:

10 April 2019 positivity. Leprosy is an endemic disease in underdeveloped or developing countries, where still a large number of cases have been reporting. Here we tried to produce the data related to leprosy in the last four years, recorded from a tertiary care hospital. A total of 619 suspected leprosy cases of both sexes were included in this study. Data related to this study was collected from laboratory registers. Privacy and confidentiality were maintained. All 619 smears of suspected leprosy cases were stained by modified ZN stain and reported. Out of 619 patient smears, 100 were leprosy positive by Modified ZN stain. Positivity of leprosy in 2018 was $17.3 \%$, in 2017 it was $17.6 \%$ in 2016 leprae cases were $14.5 \%$ and in 2015 it was $10.6 \%$. Majority of the cases were observed in the age group of 21-40 years followed by 41-60 years. In 2018 positive cases of leprosy among children below 10 years of age and geriatric age group was $6.9 \%$ and $6.9 \%$ respectively. More research works on HD helps us to eliminate leprae bacilli and early diagnosis of HD along with education programmes aids in preventing HD associated disability.
\end{abstract}

\section{Introduction}

Leprosy is an ancient disease affecting thousands of people since many years. Mycobacterium leprae (M. leprae) is becoming a most outstanding bacteria, due to its features such as persistent infectious bacteria and DNA genome has changed very little over the centuries [1].

Leprosy is a curable disease, also known as Hansen's disease, caused by a slow-growing intracellular bacteria called Mycobacterium leprae. It has prolonged incubation period [2]. Leprosy is no more a social stigma in India because of government support by wide awareness campaigns, free investigations for diagnosis, free treatment and rehabilitation centres. In the rural area, it is still a stigma facing many social problems such as fears of ostracism, loss of employment or expulsion from family and society, but people do realize that the disease is curable.

Multi-drug therapy effectively works if it started early, helps to make them non- 
infectious. Preventive measures help to decrease the number of leprosy cases. Screening of the patient's family for leprosy is an important step to reduce the incidence of leprosy and also helps family members to get early treatment after skin smear test positivity [3]. People have to take measures like improving immunity, maintaining hygiene, should avoid overcrowding. Educating from the school level is the most important for the eradication of the disease. Even if it is cured, physical and neurological damage may be irreversible. That's why early detection is more important [3].

Still the precise mechanism of transmission of $M$. leprae is not known. Even laboratory investigations have not yet developed for early diagnosis of disease. The gold standard for detection of leprae bacilli is full skin biopsy. Effective vaccines are development and still under clinical trials.

Leprosy is an endemic disease in underdeveloped or developing countries, where still a large number of cases have been reporting. Worldwide, 219075 new cases were detected in 2011[4]. New leprosy cases were 211009 in 2017 globally, according to official figures from 159 countries from the 6 WHO regions [5]. Here we tried to produce the data related to leprosy in the last four years, recorded from a tertiary care hospital.

\section{Materials and Methods}

The present study was a retrospective study, carried out during January 2015 to December 2018 at Department of Microbiology, Government Medical College, Kurnool. A total of 619 suspected leprosy cases of both sexes were included in this study. Data related to this study was collected from laboratory registers. Privacy \& confidentiality were maintained. All the clinical and epidemiology details obtained from these leprosy cases through a requisition form of $\mathrm{ZN}$ stain have been entering regularly in laboratory registers along with interpretation of reports.

Split skin smears along with requisition form for $\mathrm{ZN}$ staining have been receiving by Department of Microbiology, regularly for detection of leprae bacilli.

All 619 smears of suspected leprosy cases were stained by modified $\mathrm{ZN}$ stain and reported. Out of 619 patient smears, 100 were leprosy positive by Modified ZN stain. Results of leprosy positive patients were recorded including relevant data, which is available in laboratory registers. These results were analyzed and the descriptive statistics were represented as numbers and percentages.

\section{Results and Discussion}

During the study period of January 2015 to December 2018, the total number of suspected leprosy cases were 619 and among these confirmed leprosy cases by modified $\mathrm{ZN}$ stain were 100 . As mentioned in Table 1 , there is an increase in the prevalence of leprosy from the year 2015 to 2018. Positivity of leprosy in 2018 was $17.3 \%$, in 2017 it was $17.6 \%$, in 2016 it was $14.5 \%$ and in 2015 it was $10.6 \%$. In the every study year, majority of leprosy positive cases were observed in Grade 2 and 3.

Majority of the cases were observed in the age group of 21-40 years followed by 41-60 years. In 2018 positive cases of leprosy among children below 10 years of age and geriatric age group was $6.9 \%$ and $6.9 \%$ respectively (Table 2 ).

The Mean age group of leprosy patients observed was $32.4 \pm 2.5$. Slight male predominance was observed among leprosy patients. $62 \%$ were males and remaining $38 \%$ were females. 16 out of 100 patients (16\%) 
were hailed from urban areas and remaining 84 patients $(84 \%)$ were from rural areas (Fig. $1)$.

Leprosy is still continuing as a significant health problem in many countries. M. leprae bacillus has an affinity for keratinocytes, macrophages and histiocytes in skin, presents clinically with dermatological features [6] and Schwann cells in peripheral nerves causes axonal dysfunction and demyelination leading to sensory loss and its consequences of disability and deformity $[7,8]$.

MultiDrug Therapy (MDT) was introduced in the year 1982, which helps to alleviate drug resistance problem and also many problems associated with monotherapy [9]. MDT consists of a combination of the medications rifampin, clofazimine and dapsone, recommended by the WHO in 1981, having a $98 \%$ cure rate $[10,11]$. Despite almost 30 years of effective MDT, the prevalence and incidence of leprosy have plateaued since 2005[12].

Hansen's disease (HD) is experiencing a high morbidity and low mortality due to long term complications. MDT treated patients comes under "immunologically cured". Even after completion of MDT, still people are facing long term consequences such as blindness or glaucoma, disfiguration of the face, erectile dysfunction and infertility in men, kidney failure, muscle weakness, permanent damage to nose and permanent damage to peripheral nerves.

One of the main reasons for requiring medical care is to manage complications like permanent neurological disability, skin \& soft tissue infections, chronic non healing ulcers, chronic leprosy reactions [13]. Neglecting treatment or delay in diagnosis can have problems associated with nerve damage more likely.
In India, a sudden drop in the incidence of leprosy was reported. Reasons for happening in endemic country like India, may be due to exclusion of recurrent cases or failure cases from prevalence rate, change in the casedefinition, pauci bacillary single dose regimen shorter duration of treatment etc., [14].

Diagnosis of leprosy is a drawback to provide early treatment and accurate diagnosis. This may be due to various reasons such as less sensitivity of ZiehlNeelsen stain, which is a staining technique routinely followed by many healthcare organizations for detection of leprae bacilli in split skin smears; No artificial media is available to support cultivation of lprae bacilli [15]; Reproduction of leprae bacilli in foot pads of mice but slowly in about 12-14 days, but animal experiment facility is required to do this investigation [16]; Electron Microscopy aids to find leprae bacilli by studying ultrastructure characteristics, EM is costly and available only in higher centres [17]; PCR diagnostic test gives exact genomic structure of leprae bacilli, but not routinely recommended because of its cost and non availability in lower resource settings [18].

Worldwide, leprosy is a still continuing challenge. Carrier plays an important role in transmission of leprosy, may be in transitional period of nasal release of bacilli [19]. Usual mode of transmission of leprosy is through inhalation of the bacilli contained in nasal secretion or flugge droplets [20]. Less commonly by skin erosions, other mode of transmission is through blood, vertical transmission, breast milk, and insect bites [21, 22]. Now - a -days, international migration also takes a part in epidemiological parameter of leprosy.

According to NLEP (National Leprosy Eradication Programme) - District wise annual case detection and prevalence as on 
March 2014 in Kurnool district was 362 new cases during 2013-2014, 8.6 ANCDR/100000 during 2013-2014, $0.53 \mathrm{PR} / 10000$ and 221 was prevalence at the end of March 2014 [23].

In the present study, Positivity of leprosy in 2018 was $17.3 \%$, in 2017 it was $17.6 \%$ in 2016 it was $14.5 \%$ and in 2015 it was $10.6 \%$. In the every study year, majority of leprosy positive cases were observed in Grade 2 and 3 . Majority of the cases were observed in the age group of 21-40 years followed by 41-60 years. In 2018 leprosy positive cases among children below 10 years of age and geriatric age group was $6.9 \%$ and $6.9 \%$ respectively. The Mean age group of leprosy patients observed was 32.4 \pm 2.5 . Slight male predominance was observed among leprosy patients. $62 \%$ were males and remaining $38 \%$ were females. 16 out of 100 patients (16\%) were hailed from urban areas and remaining 84 patients $(84 \%)$ were from rural areas.

Visweswararao et al., [24] did a study in Kurnool division by random sampling method, documented $63.04 \%$ were males and $36.9 \%$ were females and also listed $\mathrm{WHO}$ grading of disability as $76.44 \%$ were grade $\mathrm{O}$, $9.06 \%$ were grade 1 and $14.50 \%$ were grade 2Syeda Mariam Seher et al., [25] did a similar to this study from Santhiram Medical College, Andhra Pradesh.

Table.1 Prevalence and bacterial grading of leprosy in between 2015 to 2018

\begin{tabular}{|c|c|c|c|c|}
\hline $\begin{array}{c}\text { Total number of } \\
\text { cases }\end{array}$ & 2015 & 2016 & 2017 & 2018 \\
\hline $\begin{array}{c}\text { No. of positive } \\
\text { cases }\end{array}$ & $7(10.6 \%)$ & $18(14.5 \%)$ & $32(\mathrm{n}=17.6 \%)$ & $43(17.3 \%)$ \\
\hline Grading & & & & \\
\hline $1+$ & 0 & 1 & 2 & 7 \\
\hline $2+$ & 3 & 3 & 4 & 10 \\
\hline $3+$ & 3 & 8 & 1 & 11 \\
\hline $4+$ & 0 & 3 & 7 & 12 \\
\hline $5+$ & 1 & 3 & 5 & 2 \\
\hline $6+$ & 0 & 0 & 1 & 1 \\
\hline
\end{tabular}

Table.2 Age wise distribution of confirmed leprosy patients from 2015 to 2018

\begin{tabular}{|c|c|c|c|c|c|c|c|c|}
\hline $\begin{array}{l}\text { Age in } \\
\text { years }\end{array}$ & $\begin{array}{l}2015 \\
(n=7)\end{array}$ & & $\begin{array}{c}2016 \\
(\mathrm{n}=18)\end{array}$ & & $\begin{array}{c}2017 \\
(\mathrm{n}=32)\end{array}$ & & $\begin{array}{c}2018 \\
(\mathrm{n}=43)\end{array}$ & \\
\hline & $\begin{array}{l}\text { No. of } \\
\text { cases }\end{array}$ & $\%$ & $\begin{array}{l}\text { No. of } \\
\text { cases }\end{array}$ & $\%$ & $\begin{array}{l}\text { No. of } \\
\text { cases }\end{array}$ & $\%$ & $\begin{array}{l}\text { No. of } \\
\text { cases }\end{array}$ & $\%$ \\
\hline $0-10$ & 0 & 0 & 0 & 0 & 1 & 3.1 & 3 & 6.9 \\
\hline $11-20$ & 0 & 0 & 2 & 11.1 & 2 & 6.2 & 4 & 9.3 \\
\hline $21-40$ & 5 & 71.4 & 8 & 44.4 & 21 & 65.6 & 23 & 53.4 \\
\hline $41-60$ & 2 & 2.8 & 5 & 27.7 & 6 & 18.7 & 10 & 23.2 \\
\hline$>60$ & 0 & 0 & 3 & 16.6 & 2 & 6.2 & 3 & 6.9 \\
\hline
\end{tabular}


Fig.1 Sex and community wise distribution of leprosy patients

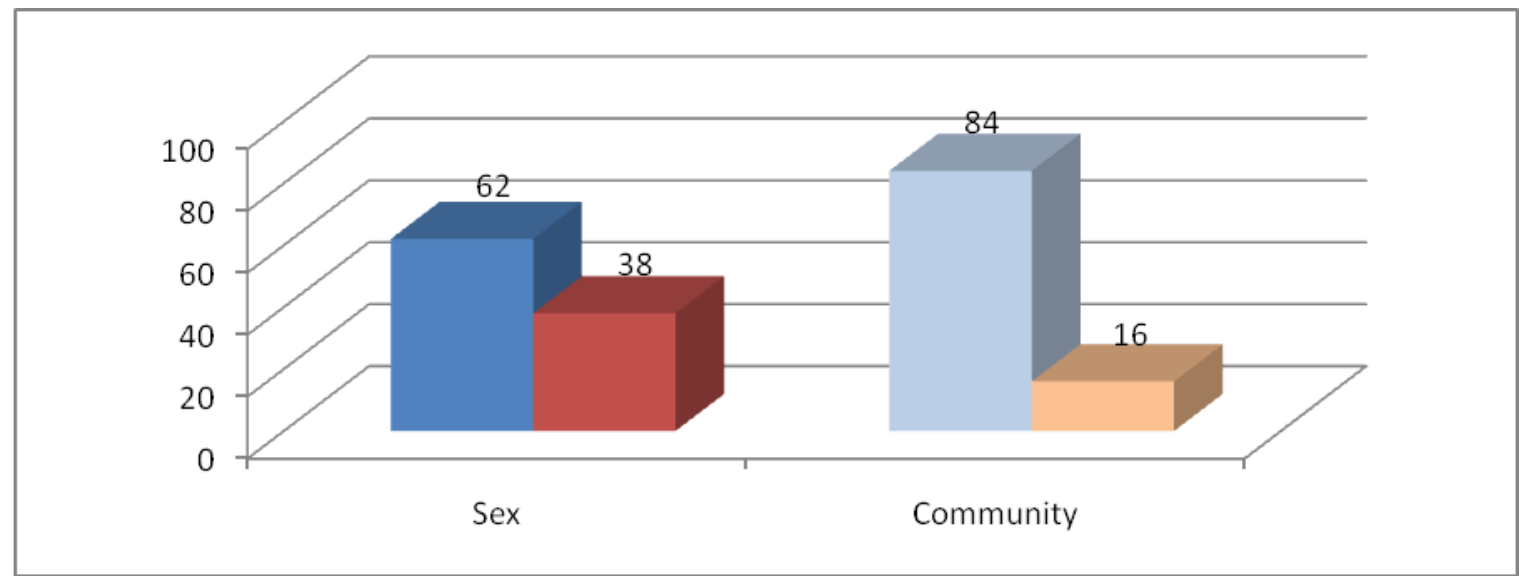

They reported male to female ratio as 1.67:1. $26.19 \%$ positivity was observed in September 2014 to August 2015 and $24.39 \%$ positivity in September 2015 to August 2016. 61.9\% belonged to age group 21-40 years, $23.8 \%$ were in the age group of 41-60 years and $14.28 \%$ were in the age group of $61-80$ years. Decrease in Incidence observed in England \& Wales between 1953-2012, more in men and the affected in the age group of 15-45 years those from Indian subcontinent [26].

"Global Leprosy strategy 2016-2020: Accelerating towards a leprosy free world", strategy which focuses on children as well as on avoiding disabilities launched by WHO in 2016 [5]. When compared with 2010, no change in number of new cases with Grade 2 disability noted in 2013, which clearly indicates a failure in early leprosy detection [27]. In 2013, the incidence of leprosy in children is $9.2 \%$, reduction was not observed, indicating transmission is clearly continuing [28]. Alarming number in identifying new leprosy cases becomes a cause of concern to officials. As symptoms take long years to show due to prolonged incubation period of $\mathrm{HD}$, early detection is difficult but awareness can help to control it. The union government is taking many steps under the NLEP I association with WHO and other international agencies. Contact surveillance, immunoprophylaxis, chemoprophylaxis, preventing drug resistance, disability prevention and rehabilitation and reducing leprosy stigmatisation helps in reducing the disease burden.

In conclusion, the incidence of leprosy still remains high and often presents with complications of this disease despite of many initiative programmes taken by government authorities and monitoring of MDT regimen. More research works on HD helps us to eliminate leprae bacilli and early diagnosis of HD along with education programmes aids in preventing HD associated disability.

\section{References}

1.Fuge O. Vasudev N, Allchorne P, Green JS. Immunotherapy for bladder cancer. Research and reports in Urology. 2015; 7; 65-79.

2.Houghton BB, Chalasani V, Hayne D, Grimison P, Brown CS, Patel MI, Davis ID, Stockler MR. Intravesical chemotherapy plus Bacille Calmette Guerin in non-muscle invasive bladder cancer: a systematic review with metaanalysis. BJU International. 2013 May; 11(6): 977-983.

3.BCG Vaccine Danish Strain 1331 - Statens Serum Institut. Ssi.dk.2013-09- 
19.Archived from the original on 201402-18.Retrieved 2014-02-02.

4. Global leprosy situation, 2012. Wkly Epidemiol Rec. 2012; 87:317-328.

5.Polycarpou A, Walker SL, Lockwood DNJ. 2013. New findings in the pathogenesis of leprosy and implications for the management of leprosy. CurrOpin Infect Dis 26:413-419. doi:10.1097/ QCO.0b013e3283638b04.

6.www.who.int/news-room/factsheets/ details/leprosy - Leprosy World Health Organization.

7.Graham A, Furlong S, Margoles LM, Owusu K, Franco-Paredes C 2010. Clinical management of leprosy reactions. Infect Dis ClinPract 18: 235238.

8..Britton WJ, Lockwood DNJ. 2004. Leprosy. Lancet 363: 1209-1219. doi:10.1016/S0140-6736(04)15952-7.

9.Gelber R, Grosset J. 2012. The chemotherapy of leprosy: an interpretive history. Lepr Rev 83: 221240.

10.Lockwood D, Shetty V, Penna GO. Hazards of setting targets to eliminate disease: lessons from the leprosy elimination campaign. BMJ, 2014; 348: g1136. doi: 10.1136/bmj.g1136.

11.Scollard DM, Adams LB, Gillis TP et al.,. The continuing challenges of leprosy. ClinMicrobiol Rev, 2006; 19: 338-381

12.World Health Organization. Global leprosy update, 2013; reducing disease burden.WklyEpidemiol Rec, 2014; 89(36): 389-400.

13.Jacob JT, Kozarsky P, Dismukes R, Bynoe V, Margoles L, Leonard M, Tellez I, Franco-Paredes C.2008. Five-year experience with type 1 and type 2 reactions in Hansen disease at a US travel clinic. Am J Trop Med Hyg 79: 452-454.

14.Talhari S, Grossi MA, Oliveira ML, Gontijo B, Talhari C, Penna GO.
Hansen's disease: a vanishing disease? Mem Inst Oswaldo Cruz. 2012; 107:1316.

15.Rees RJW, Young DB. The microbiology of leprosy. In: Hastings RC, editor. Leprosy. 2nd ed. New York: Churchill Livingstone; 1994. pp. 49-83.

16. Nolte FS, Metchok B. Mycobacterium. In: Murray PR, Baron EJ, Pfaller MA, Tenover FC, Yolken RH, editors. Manual of clinical microbiology. 6th ed. Washington: American Society for Microbiology; 1995. pp. 400-437.

17.Draper P. The bacteriology of Mycobacterium leprae. Tubercle. 1983; 64: 43-56.

18.Cole ST, Eiglmeier K, Parkhill J, James KD, Thomson NR, Wheeler PR, et al.,. Massive gene decay in the leprosy bacillus. Nature. 2001; 409: 1007-1011.

19. Van Beers SM, de Wit MY, Klatser PR. The epidemiology of Mycobacterium leprae: recent insight. FEMS Microbiol. Lett. 1996; 136: 221-230.

20.Shepard CC. The nasal excretion of Mycobacterium leprae in leprosy. Int J Lepr. 1962;30:10-18.

21.Santos AR, Balassiano V, Oliveira ML, Pereira MA, Santos PB, Degrave WM, et al.,. Detection of Mycobacterium leprae DNA by polymerase chain reaction in the blood of individuals, eight years after completion of antileprosy therapy. Mem Inst Oswaldo Cruz. 2001; 96:1129-1133.

22.Pedley JC. The presence of M. leprae in human milk. Lepr Rev. 1967; 38: 239242.

23.www.nlep.nic.in. District wise annual new case detection and prevalence as on March 2014.

24.VisweswaraRaoGuthi, SreedeviArepalli, Praveena Ganapa. Study of socio demographic factors among persons affected by leprosy in Kurnool division of Kurnool district, Andhra Pradesh, 
India.Int $\mathrm{J}$ Community Med Public Health. 2016 Dec; 3(12): 3548-3555.

25.Syeda Mariam Seher, Sanikommu Sreedevi, Gls.Sumath, Jinka Balakrishna, Satta Naga Sireesha, Mogalapu Anand Satya Tej. Current scenario of smear-positive leprosy cases in a rural tertiary care hospital in Nandyal, Andhra Pradesh. J evolution Med Dent Sci. 2017 Apr; 6(34): 22784748.

26.Nicholas Fulton, Laura F Anderson, John M Watson, Ibrahim Abubakar. Leprosy in England \& Wales 1953-2012:
Surveillance \& challenges in low incidence countries. BMJ. 2015; 6(5): 10.1136.]

27.World Health Organization. Global leprosy update, 2013; reducing disease burden. Wkly Epidemiol Rec, 2014; 89(36): 389-400.

28. World Health Organization. Leprosy Prevalence Rates. World Health Organisation Map Production: Control of Neglected Tropical Diseases. http://www.who.int/lep/situation/Lepros y_PR_2011.pdf?ua $1 \frac{1}{4} 1$. Published 2012.Accessed October 1, 2014.

\section{How to cite this article:}

Valluri Anitha Lavanya, Rachamadugu Hymavathi, A. Surekha and Soumya, C. N. 2019. Increasing Trends of Leprosy - Still a Public Health Challenge. Int.J.Curr.Microbiol.App.Sci. 8(04): 963-969. doi: https://doi.org/10.20546/ijcmas.2019.804.111 